Reviewed Article

THE FAMILY LAW CLINIC AT UCC - UNDERSTANDING THE LAW, IN THE

\title{
CLASSROOM AND BEYOND
}

\section{Louise Crowley*}

\section{Introduction}

Shulman extols the benefits of 'empirical propositions' ${ }^{1}$ emphasising the value of interrogating teaching approaches with a view to establishing evidence as to how students learn, and in turn crafting effective ways to teach. This article critically explores the design and assessment approaches adopted in the delivery of the Family Law Clinic Module at the Law School, University College Cork and interrogates the impact of these approaches on student learning. In carrying out this action research, the decision to utilise Universal Design for Learning as the underlying Scholarship of Teaching and Learning framework allows the pedagogical approach adopted to be deconstructed and critically examined. The capacity for student involvement in the teaching journey which is premised upon the ideology of learning and teaching as community property will be explored, both from a theoretical perspective and also from a socio-legal viewpoint. It will be shown that empowering the students to direct the module and assessment content serves to awaken their social awareness and their understanding of their role as pro-social contributors. Following an exploration of these aspects of SOTL thinking, the

\footnotetext{
${ }^{*}$ Louise Crowley is Senior Lecturer at the School of Law, University College Cork, Ireland.

${ }^{1}$ Shulman LS The Wisdom of Practice: Essays on Teaching, Learning and Learning to Teach (ed. Wilson S)

(2004) (San Francisco) Jossey-Bass at 148, 149.
} 
student learning experience will be explored through a number of qualitative research methods, namely individual student interviews post completion of the module, individual student reflective journals and the testimonial experience of external parties who utilise the Family Law Clinic research services. These approaches to understanding the student experience will serve to demonstrate the unique approach adopted in the Family Law Clinic that gives rise to a unique student learning environment and holistic student development.

\section{Methodology}

Researching the Clinical Legal Education experience is very necessary "to ascertain whether it does offer the skills and insight into a practical vision of legal practice which classroom education fails." ${ }^{2}$ In measuring the 'success' of the Family Law Clinic as an innovative and progressive pedagogical approach to the teaching and learning of family law, the experience of both its students and external partners have been explored through a number of qualitative methods. Reflective journals are maintained by the students during the delivery and completion of the module, and these personal student reflections are investigated to determine the impact of the Clinic. As research methods, these reflections have been supplemented by individual interviews with students upon completion of the module, ${ }^{3}$ to further interrogate

\footnotetext{
${ }^{2}$ Marson J, Wilson A, Van Hoorebeek M; "The Necessity of Clinical Legal Education in University law Schools: A UK Perspective" [2005] Journal of Clinical Legal Education 29-43 at 30. http://shura.shu.ac.uk/2902/1/Marson\%2C wilson - Necessity of clinical legal education.pdf ${ }^{3}$ Ethical approval was secured from the UCC Social Research Ethics Committee to invite students who had completed the module to participate in this research on the impact of the Family Law Clinic
} 
their learning experience. ${ }^{4}$ The external assessment of the student efforts and the impact of their work will be commented upon by the Clinic's clients; legal practitioners and those engaged with law reform activities, together with the informed academic expertise of the module external examiner. These qualitative research methods will facilitate a critical analysis of the impact of this pedagogical approach which aligns with the view that learning lies not only in understanding the law and legal principles in their own right, but by elevating that knowledge to an awareness of its application in practice, which Schon suggests exposes students to "a kind of rigor that falls outside the boundaries of technical rationality". ${ }^{5}$

as a pedagogical approach to teaching and learning. The participation was voluntary, and all data was anonymised for the purposes of analysis. The following approved indicative question were provided in advance to the students, and these were the question posed to the participating students at interview:

1. Have you previously taken a module which required you to develop legal resources for the community?

2. Do you think students have a contribution to make in the law-making process?

3. What insights have you gained into the role and responsibilities of a family law solicitor?

4. From your experience of law in action during the Family Law Clinic, how accessible do you regard the legal system for Irish people?

5. How crucial is access to information in securing access to justice?

6. What are the pros and cons of providing an online information hub on all aspects of family law?

7. Can you reflect on your learning experience through completing the Family Law Clinic?

${ }^{4}$ The interviews are voluntary in nature, and do not form any part of the module assessment requirements. The reflections and feedback inform the annual review of the Family Law Clinic which is critical to ensure that quality enhancement is always to the forefront of the module review. It is well recognised that as an approach to analysis and research that "interviews give rich, insightful, albeit anecdotal evidence about how people feel and act. Interviews provide persuasive insights and direct quotes from people who "were there." "How to Conduct Interviews for Research" - Designing Information to Engage, Educate and Inspire people https://thevisualcommunicationguy.com/2018/01/30/how-to-conduct-interviews-for-research/

${ }^{5}$ Donald A Schon "Knowing in action - The New Scholarship Requires a new Epistemology" Change Nov/Dec 1995 at 29. 


\section{Clinical Legal Education}

The Family Law Clinic at University College Cork was developed to provide students in the LLM (Children's Rights and Family Law) with the opportunity to contribute to the "intricate ecosystem of legal advice" ${ }^{6}$ within the Irish legal system. In Ireland, the professional legal services regulations restrict the capacity for a university-based law clinic to provide legal advice directly to the public and consequently such clinics more typically provide research services to legal professionals who utilise that research as part of their representation of their clients. ${ }^{7}$ The provision of information to the general public, as distinct from advice, is entirely permissible and the students fulfil this role through taking responsibility for the content of the dedicated Clinic online information hub and related resources, outlined below.

Whilst students attend university primarily to gain a knowledge and insight into their chosen discipline, to graduate and progress their career, the understanding of what that career choice entails can often be lacking given the limited scope of classroom-based learning. The exposure of students to the functioning of the legal

\footnotetext{
${ }^{6}$ Drummond $\mathrm{O}$ and McKeever G "Access to Justice through University law Clinics" Ulster University Law School (2015) at 14. https://www.ulster.ac.uk/ data/assets/pdf file/0003/132654/Access-toJustice-through-Uni-Law-Clinics-November-2015.pdf

${ }_{7}$ Section 46(1) of the Legal Services Regulation Act 2015 mandates that legal practitioners (defined as a practising solicitor or practising barrister) must hold professional indemnity insurance to lawfully provide legal services, including legal advice. Legal advice is defined as Any oral or written advice ...but does not include an opinion on the application of the law provided by a person to another person in the course of - (i) lecturing in our teaching an area of the law, as part of a course of education or training.
} 
system through the clinic work permits students to better understand and make more informed choices about their next steps post-graduation. More altruistically, the Clinic also provides students with the opportunity to act as information providers and conduits to accessing justice, providing knowledge and supports to individuals who might otherwise struggle to penetrate the complex justice system. Wilson has described clinical legal education as the "greatest single innovation in law school pedagogy - and certainly in student learning - since the 'science' of the Socratic case method was brought to Harvard by Christopher Columbus Langdell." 8 Donnelly in a 2015 report "Clinical Legal Education in Ireland: Progress and Potential" ${ }^{\prime}{ }^{9}$ presents a cross-section of clinical legal education programmes in Ireland. He identifies three models of clinic-based learning in Irish universities; the placement/internship model which is the most common and least demanding in terms of university resources; the street law clinic which emphasises the provision of information to the public in an attempt to enhance access to justice and the more novel live client model which is slowly developing in Ireland. ${ }^{10}$ Donnelly's report interrogates the work of 10 Irish law schools, as well as the approaches adopted by the Law Society of Ireland, the School of Law at Ulster University and Northumbria Law School. Evidently, as an approach to teaching, law school clinics are growing in popularity in Irish universities. Clinical education at UCC is expanding with the

\footnotetext{
8 Wilson R "Western Europe: Last Holdout in the Global Acceptance of Clinical Legal Education" (2009) 10 German Law Journal 823 at 823.

${ }^{9}$ Donnelly L "Clinical Legal Education in Ireland: Progress and Potential” [2015] NUIG.

http://www.nuigalway.ie/media/nuigalwayie/content/files/collegesschools/businesspublicpolicylaw/d ocumentsforms/Clinical-Legal-Education-Report.pdf

${ }^{10}$ Ibid at 6.
} 
School of Law now operating 5 clinics, one at undergraduate level and four at masters level ${ }^{11}$ as well as a dedicated undergraduate BCL (Clinical) degree programme. ${ }^{12}$

The range of issues covered by law clinics varies enormously and is very often dictated by the research and teaching interests of the clinic directors. Additionally, the services provided by clinics will vary, ranging from research services, information provision, advice, and advice and representation. Irish clinics also contribute submissions that inform policy and law development at national level as well as contributing to the work of NGOs and other such organisations. The 2015 Report on the nature and breadth of UK based university law clinics suggests a much greater engagement with individual clients, both in the provision of advice only and in a smaller number of clinics, the provision of advice and representation. Clinical education is thus rightly recognised as a vital component of the development of skills and knowledge in an impactful and "authentic" learning environment. ${ }^{13}$ Indeed Donnelly

\footnotetext{
${ }_{11}$ The Child Law Clinic, Environmental Law Clinic, Family Law Clinic and IT Law Clinic at postgraduate level and the Sports Law Clinic at undergraduate level.

${ }^{12}$ In their 2015 survey Drummond and McKeever document the 62 university law schools in the United Kingdom which operate law clinics, supra n.2 at 5.

${ }^{13}$ Vaughan B "Developing a clinical teaching quality questionnaire for use in a university osteopathic pre-registration teaching program" [2015\} BMC Medical Education 1-13 at 1.

https://bmcmededuc.biomedcentral.com/articles/10.1186/s12909-015-0358-6
} 
“...unapologetically endorses the popular perspective that clinical legal education is at its best when it is simultaneously purposed to combine 1) the "hands on" teaching and augmenting of practical skills with 2) the advancement of the public interest by endeavouring to improve access to justice for all." 14

\section{Scope and Activities of LW6614 - Family Law Clinic}

The 5-credit module Family law Clinic was first delivered to the LLM (Child and Family Law) students in semester 1 2015/16 ${ }^{15}$ and involves 12 teaching hours over the semester. Generally this consists of six 2 hour seminars, beginning with the annual development and enhancement of the website and related discussions in respect of access to information and justice. The scheduling of the remaining seminars is, for the most part, determined in response to external requests for research support. The tasks undertaken by the Clinic are four-fold; ${ }^{16}$ student contribution to the development and publication of the web-based family law information hub; individual student blogs on contemporary family law issues, contribution to research projects including live family law cases; and the writing of

${ }^{14}$ Supra n. 4 at 6 . Clinic-based education is not unique to law, much research has been conducted in relation to clinical education in the healthcare professions. In a study of the theories that underpin clinical education in physiotherapy, Patton et al describe workplace learning as "practice, social learning, situated learning and reflective/critical thinking", which interestingly reflect the components of workplace learning in the Family Law Clinic. Patton N, Higgs J, Smith M "Using theories of learning in workplaces to enhance physiotherapy clinical education" [2013] 88 (6) Physiotherapy Theory Practitioner 861-865.

${ }^{15}$ The LLM (Child and Family law) was renamed the LLM (Children's Rights and Family Law) in the 2018/19 academic year.

$1650 \%$ of the module marks are awarded in respect of student participation and class contribution, $25 \%$ for the individual learning journal and $25 \%$ for their blog post. 
individual reflective learning journals on the student clinic experience. This novel combination of engagement and assessment requires the students to develop skills outside the norm of the lecture room, mandating them to take ownership of their areas of responsibility and to challenge themselves to share their critical understanding of their chosen aspects of family law with the broader public. The flagship piece of work of the Family Law Clinic has been the family law information website - $\underline{w w w . f a m i l y l a w i n f o r m a t i o n . i e}$. This is a new and unique online resource which acts as a central hub for interested parties, by providing a comprehensive information resource on all aspects of family law, including the regulation of marriage, civil partnership and cohabitation, guardianship, custody and access, domestic violence, adoption, relationship breakdown, and all aspects of state provision for families. Students of the Clinic are tasked with updating the information pages annually, empowering them to address the misinformation and myths surrounding family law, thereby bridging the family law information vacuum that exists in Irish society. The website as an information platform was funded by the Irish Research Council under the 2013 New Foundations scheme. ${ }^{17}$ Separately, in March 2020, at the beginning of the COVID-19 pandemic, the 2019/2020 Clinic

\footnotetext{
${ }^{17}$ The choice to develop the web-based resource was informed following significant consultation with interested parties. Funding was originally sought under an Irish Research Council funding call for the creation of information pamphlets for distribution to the general public both directly and through state support agencies. However following a round-table workshop at the Law School in September 2014 which was attended by public interest bodies, NGOs, the Court Services, Legal practitioners and members of the Irish judiciary, it became very apparent that many state services including FLAC, Citizen Advice Bureau and One Family already publish a range of relevant information documents. It emerged that the challenge to be addressed was ensuring that a member of the public was aware that these documents exist and could easily access them. It was agreed that by far the most effective development would be to create an online hub that would provide a brief insight into each area of family law, and a roadmap to all relevant State support services and information sources.
} 
students supported the creation of a dedicated family law COVID-19 information hub website, to provide a resource for the public in respect of the revised access and support arrangements in the course of the pandemic. ${ }^{18}$

The information website is further supplemented with a topical blog post written by each student, addressing a current issue arising in the area of family law, providing an up to date insight into a socially relevant issue of the day. ${ }^{19}$ These blogs are posted on the website and publicised through the Family Law Clinic twitter account. ${ }^{20}$ They are also assessed, and contribute to the students' final grade for the module, representing $25 \%$ of the overall mark. ${ }^{21}$ In contributing to the development and maintenance of the website the students of the Family Law Clinic have been stretched beyond the normative experience of a law student, developing an ability to write not just as a lawyer, but as an information provider to those with little or no understanding of the law. This need to make the law accessible challenges their own

\footnotetext{
${ }^{18}$ https://www.ucc.ie/en/covid19familylaw/

19 The blog posts submitted by the 2018/19 Family Law Clinic were entitled as follows:

- Supporting the Deaf Community - Cultural Change is Needed.

- How long is too long in Emergency Accommodation?

- Guardianship

- Divorce - the living apart requirement

- Legal Rights for grandparents

- Pre-Implantation Genetic Diagnosis and Reproduction

- Coercive Control - the overdue recognition of psychological abuse

- The benefits of mediation

- Do children have a right to inherit?

- Adoption Information and Tracing Bill: Right to Identity v Right to Privacy

- $\quad$ The proposed reform of the Family law Courts System in Ireland

- Adoption

$20 @$ uccfamlawclinic

${ }^{21} 25 \%$ of the overall marks are awarded for the student blog and $50 \%$ for the student contribution and effort over the course of the module.
} 
perceptions and understanding of the law and activates a very real sense of social responsibility. Separately they are also tasked with conducting research for legal practitioners to inform and enhance court applications, and/or policy-based research dossiers as requested by a range of service providers and NGOs. The research projects are crafted in response to external requests received from legal practitioners, non-governmental organisations, support services and lobby groups and form a key element of the student learning. Student efforts in respect of these research projects are assessed alongside class participation, such participation being encouraged through individual presentations on allocated advance reading, as well as spontaneous contributions to class discussion and guest speakers.

Finally, students are required to maintain a learning journal which provides them with the opportunity to document their activities and reflect on their learning journey throughout the duration of the Family Law Clinic. By requiring students to engage with both the explanatory and reflective elements of their learning experience, they are encouraged to explore not just the learning in itself, but also to consider the impact of that learning on themselves and on those targeted by the various exercises, developing their awareness of the law in practice, the challenges faced by those who have restricted or indeed no access to information and/or justice and the very real, positive impact of their efforts on individuals, law and policy reform, and on the standards of advocacy in family law cases. The student experiences of completing a reflective learning journal are considered below. 


\section{Interrogating the Family Law Clinic as a form of scholarship}

The activities, student learning and research in action arising from the Family Law

Clinic are in themselves a valuable form of scholarship. Schon builds upon Boyer's four platforms of scholarship which collectively form his view of the "new forms of scholarship", promoted by Boyer as necessary to challenge the historical epistemology of the modern research university. Boyer's view of the new forms of scholarship comprises four distinct elements. Building upon his original premise of scholarship of discovery representing "the first and most essential form of scholarship", he subsequently identified three additional forms of scholarship:

- Scholarship of integration - what Boyer regards as "serious, disciplined work that seeks to interpret, draw together, and bring new insight to bear on original research." 22

- Scholarship of application - regarded by Boyer as representing the move towards engagement, as the scholar considers how knowledge gained can be applied to problems, and even further querying whether "social problems themselves define an agenda for scholarly investigation?" 23 Boyer posits the principles of the early $20^{\text {th }}$ century that higher education must serve the interests of the larger community. However, he laments that "all too

\footnotetext{
${ }^{22}$ Boyer EL Scholarship Reconsidered-Priorities of the Professoriate (San Francisco Jossey-Bass Publishers 1990) at 19. Boyer cites favourably the views of Van Doren who 30 years earlier had written that "The connectedness of things is what the educator contemplates to the limit of his capacity. No human capacity is great enough to permit a vision of the world as simple, but if the educator does not aim at the vision no one else will, and the consequences are dire when no one does." It is, Boyer notes, "through connectedness that "research" is ultimately made authentic." Van Doren M Liberal Education (Boston Beacon Press 1959) at 115.

${ }^{23} \mathrm{Ibid}$ at 21.
} 
frequently, service does not mean doing scholarship but doing good", implying that the two distinct worlds are unlikely to collide. The very raison d'etre of the Family Law Clinic is to dispel this notion through a deliberate learning in action for impact approach.

- Scholarship of teaching - Rather than being regarded as "a routine function" Boyer quotes Aristotle's assertion that "Teaching is the highest form of understanding". ${ }^{24} \mathrm{He}$ also references Palmer, who regards knowing and learning as "communal acts" ${ }^{25}$ Commending the scholarship of great teachers he applauds them as they "stimulate active, not passive learning and encourage students to be critical, creative thinkers, with the capacity to go on learning after their college days are over." 26

Schon suggests that this approach places an onus on scholars producing the knowledge to do so in a robust rigorous way that validates the scholarship. This in Schon's view demands "a kind of action research" which challenges the existing norms of technical rationality and extends the knowledge transfer and exploration to a new epistemology, a new theory of knowledge premised upon novel methods of learning with broader, indeed braver scope. The Family Law Clinic provides a unique forum for this new epistemology, compelling students to consider both their acquired classroom knowledge in the context of the law in practice. It operates to

\footnotetext{
${ }^{24}$ Ibid at 23.

${ }^{25}$ Ibid at 24, quoting Palmer P To Know As We Are Known (New York: Harper \& Row, 1983)

26 Ibid.
} 
shift the student learning from the "high, hard ground [where] manageable problems lend themselves to solution through the use of research-based theory and technique" to the "swampy lowlands [where] problems are messy and confusing and incapable of technical solution." 27

This capacity to encourage intelligence in action, to provide students with the forum to discover the epistemology of practice, that "takes full account of the competence of practitioners...in situations of uncertainty, complexity uniqueness and conflict" 28 directs the students towards the "swampy lowlands" challenging them in new and innovative ways.

"I found the Clinic to be a very enjoyable experience. Traditionally, modules I have taken over the course of my undergraduate degree and postgraduate degree help me to understand the law, however, none of them have allowed me to contribute to the law in the way the Clinic has done. The engagement with practicing solicitors and the public was something that I have not had the chance to do before." 29

\footnotetext{
${ }^{27}$ Donald A Schon "Knowing in action - The New Scholarship Requires a new Epistemology" Change Nov/Dec 1995 at 28.

${ }^{28}$ Ibid at 29.

29 Student A - Learning Journal.
} 
Schon regards these new forms of knowledge and action research as crucial to defending the view that teaching is in itself a new form of scholarship. This emphasis on action research is evidently suited to the work of the Clinic given the reliance upon multiple forms of engagement with end users; the provision of information to the general public, the research activities on behalf of charitable and non-governmental organisations; the engagement with topical legal issues and publication for public consumption; the policy submissions on emerging areas of family law and law reform; and the pro bono case-specific legal research to enhance advocacy standards in the pursuit of individual and family rights. Certainly, in light of Schon's views of action research being the new scholarship, the development and maintenance of the family law information website by the Director and students of the Clinic can be identified as a form of scholarship in itself. This new scholarship implies action research, and in this context the Clinic has a dual mandate - learning in action is evident amongst the students, but equally the research into the Family Law Clinic module and its approach to the delivery of the learning serves as research in action, placing the impact of these innovative practices under constant review both as to how they are delivered as well as how they impact on the student learning experience.

"If teaching is to be seen as a form of scholarship, then the practice of teaching must be seen as giving rise to new forms of knowledge. If community outreach is to be seen as a form of scholarship, then it is 
the practice of reaching out and providing service to a community that must be seen as raising important issues whose investigations may lead to generalisations prospective relevance and actionability. If we speak of scholarship of integration - the synthesis of findings into larger, more comprehensive understandings - then we are inevitably concerned with designing." 30

In promoting a more inclusive and imaginative approach to the concept of teaching, Bass has called for a fundamental shift in "how one defines teaching as an activity and thus as an object of investigation." ${ }^{31}$ He regards the scholarship of teaching as including a "broad vision of disciplinary questions and methods...[including] the capacity to plan and design activities that implement the vision...the interactions that require particular skills and result in both expected and unexpected results." Citing Shulman, he agrees that "Too often teaching is identified only as the active interactions between teacher and students in a classroom setting....I would argue that teaching like other forms of scholarship, is an extended process that unfolds overtime" and Bass endorses his view that this process embodies at least five elements: vision, design, interactions, outcomes and analysis. ${ }^{32}$ Ultimately, in crafting the Family Law Clinic and incorporating multiple modes of delivery,

\footnotetext{
${ }^{30}$ Supra n.19 at 31.

${ }^{31}$ Bass R The Scholarship of Teaching: What's the Problem? [1999] 1 Creative Thinking About Learning and Teaching

${ }^{32}$ Ibid, citing Shulman L "Course Anatomy: The Dissection and Analysis of Knowledge through Teaching" The Course Portfolio: How Faculty Can Examine Their Teaching to Advance Practice and Improve Student Learning. 5-12 at 5.
} 
student expression and assessment methods, the Clinic experience can evolve annually as it responds to legal developments, student contributions and external engagement. As distinct from the restrictions and confines of a set examination, utilising the website as a key learning tool provides the scope to observe how we "do" our thinking, moving students away from "just thinking". Citing Kegan and Lahey, ${ }^{33}$ Blackshields notes that in this environment, the students and the lecturer can collectively explore their pre-existing assumptions and ultimately integrate practice and theory to allow the students to develop from one way of knowing to another. ${ }^{34}$ In recognising the social inequalities which can prevent real access to information and thus blockading true access to justice, this journey pushes them towards a greater understanding of their role as law students and as future lawyers, and their capacity to bridge that gap. Thus, they are tasked with developing an understanding as to the nature and extent of the issue of information availability, and assessing the impact of the lack of access, and in turn determining how this might best be remedied through their efforts. This approach means that no two clinic years are ever the same - the end goal is agreed, namely access to information in order to facilitate access to justice, together with contribution to law and policy reform. Together the problem and the parameters of the task in hand are shared, the

\footnotetext{
${ }^{33}$ Kegan R., Lahey L.L. "From Subject to Object: A Constructive-Developmental Approach to Reflective Practice" In: Lyons N. (eds.) Handbook of Reflection and Reflective Inquiry. Springer, Boston, MA 2010 at 434.

${ }^{34}$ Blackshields D CIRTL presentation at Creative Zone, University College Cork 21 November 2017.
} 
seminar room for the Family Law Clinic module becomes that shared community, to investigate the issues and to craft the student responses.

Bass $^{35}$ and Shulman ${ }^{36}$ are both vocally critical of the traditional view of teaching as a private endeavour, considered in more detail in the discussion on learning and teaching as community property below. Bass regards an interactive approach to teaching as enabling teachers to not only "know these things" but to have them presented in serious and impactful ways. This in his view encapsulates the essence of the scholarship of teaching.

"Changing the status of the problem in teaching from terminal remediation to ongoing investigation is precisely what the movement for the scholarship of teaching is all about." 37

In the process of completing the Family Law Clinic module, students move beyond a basic need to understand and apply the law for knowledge sake. and recognise their capacity to utilise their learning for more than just that.

\footnotetext{
${ }^{35}$ Supra n. 23.

${ }^{36}$ Shulman L "Teaching as Community Property - Putting an End to Pedagogical Solitude" [1993] 25 Change 6-7. http://depts.washington.edu/comgrnd/ccli/papers/shulman1993TeachingAsCommunityProperty.pdf 37 Supra n.23.
} 
"The Clinic completely bridged the gap between the theory and what is happening in practice. It demonstrated to me that our work in UCC carries over to practice.... It allowed me to grasp the theory more effectively, helping me to better understand rather than 'slug' through books and articles alone." ${ }^{38}$

By asking the students to accept their responsibility to provide access to legal information, to gauge the public need and respond through updating the website and writing a blog, the students can 'check in on themselves' and better understand their capacity to provide access to legal information and in turn to contribute to the public capacity to engage with the law and ultimately to access justice. In so doing the students are ultimately challenged to both understand and contest the assumptions that they and society typically make, and to recognise the elements that facilitate true access to justice and the underlying importance of knowledge, made possible through accessible and available information.

"The experience of this module helped my confidence in myself in that the module was "alive" -in that the class linked in with ongoing practice issues, "real" in that it reflected the reality of a poorly

\footnotetext{
${ }^{38}$ Student C. Similarly, Student D reported: “While carrying out the work for the Clinic I found new ways of utilising my legal knowledge and skills for the benefit of others who seek legal advice and direction. I learned the importance of using this knowledge to provide quick information to people who require it because of a particular situation that has occurred in their lives."
} 
resourced legal system but also highlighted the tenacity of clients in accessing services and the commitment of the people providing the legal services. Finally, it facilitated incremental learning and reflective practice, an experience I had gained in my family therapy training." 39

This approach requires group work and collaboration between the students, who have the autonomy to decide the role of each student within each group-based task. This deliberate move away from the traditional independent endeavours of law students caused some trepidation for students "...Initially I was a little hesitant about the prospect of group work...", but serves to both activate and cultivate the important skills required for effective group-based collaboration and has proven a challenge that is successfully embraced by the students, both in terms of experiences and outcomes.

“The format in which this module was delivered was particularly enjoyable and I feel beneficial to my learning. Within the module we sat around a circular table and the class was for the most part discussion based. The open and informal way in which the class was delivered gave a relaxed feel in which I felt more confident to express my point, ask questions and interact with my classmates - this I feel was very beneficial and a fantastic element of the module. Furthermore, the conversational nature of the Clinic allowed for a

\footnotetext{
39 Student K.
} 
great scope of material to be covered in an interesting and insightful way, I really enjoyed hearing my classmate's experiences and views and I feel it greatly added to my learning. ${ }^{40}$

\section{Utilising Universal Design for Learning to maximise student learning}

Universal Design for Learning (UDL) highlights the importance of the well designed, multi-faceted learning environment, which, where properly planned will in the course of the initial module design identify and incorporate the needs of the diverse student population likely to register for the module, and in so doing avoiding any need for post-commencement adaptation. The student 'audience' in the Family Law Clinic is comprised of students from a diverse range of academic and practice backgrounds. Annually we have an intake of 10-15 students, with typically half of the cohort being recent law graduates and the remainder coming from professions and practices relating to children rights and family law. In addition to the naturally occurring multiple intelligences amongst all students, this variety of student knowledge and experience further adds to the variance in learning approaches and capacities in the room. The fact that this class is comprised of such diverse learners demonstrates the importance of recognising and accommodating multiple intelligences when developing the module content, delivery and assessment elements. Some of the students who work in the professions study on a full-time basis and others take the LLM on a 2 year part-time basis with reduced

${ }^{40}$ Student D - Learning Journal. 
hours of practice. Thus, the module as structured operates to welcome, support and nurture every student and their individual capacities. The importance of accessible learning cannot be over emphasised, incorporating accessibility not only in terms of information but also pedagogy - the design and delivery of the module needing to support learning by all. Rose et al emphasise that utilising UDL is an important acknowledgment of the importance of the individual learner, who works and learns both individually and within the class based group environment, and where properly utilised, results in a student-centric diverse approach to learning and teaching. ${ }^{41}$

Meyer and Rose of the Centre for Applied Special Technology (CAST) assessed the original seven tenets of universal design thinking and its application within the education context. In so doing, whilst recognising the suitability of UDL to programme design, they extrapolated three principles as necessary for the creation of an accessible and wide-ranging module.

“The framework for UDL...embeds accessible pedagogy into three specific and central considerations in teaching: the means of

\footnotetext{
${ }^{41}$ Rose D, Harbour W, Johnston C, Daley S and Abarbanell L. “Universal Design for Learning in Postsecondary Education: Reflections on Principles and their Application" [2006] 2 Journal of PostSecondary and Disability, 19, 135-151 at 136. https://files.eric.ed.gov/fulltext/E]844630.pdf
} 
representing information, the means for students' expression of knowledge, and the means of engagement in learning." 42

The first principle advocated by Meyer and Rose is the multiple means of representation. This is an acknowledgement of the responsibility of the lecturer, to present the module learning in multiple ways, to ensure that every student has at least one means of successfully receiving the information, given that students differ in the ways that they receive and understand the information that is presented to them. Rose et al reference the many ways and reason for such disparity;

"At the extreme are students with disabilities (e.g., those who are blind or deaf), for whom some forms of presentation are completely inaccessible. More prevalent are students who, because of their particular profile of perceptual or cognitive strengths and deficits, find information in some formats much more accessible than others (e.g., students with dyslexia, aphasia, mental retardation). Even more common are students with atypical backgrounds in the dominant language, cognitive strategies, culture or history of the average classroom who, therefore, face barriers in accessing information when 
presented in a manner that assumes a common background among all students." 43

The disparity in starting points of the Clinic students, both in terms of knowledge and experience, as well as the learning capacities of each student mandates that multiple approaches to presentation are utilised, including prior reading, lecturer delivery of overview, student presentation to facilitate peer-to-peer learning, visual presentation through PowerPoint presentation, use of digital technology and groupbased class discussions. Seminars are structured to allow each student, the opportunity to present on, and lead the discussion on a pre-identified topic. This serves a number of learning objectives, firstly; the student leading the discussion, with plenty of notice can prepare with advance reading and is given the opportunity to practice their advocacy and presentation skills, albeit in the relatively safe and familiar environment of this small group of students. Secondly fellow students can equally prepare by reading the material in advance, can ask questions of the student presenter and/or engage with the learning from listening to the oral presentation on the day. Additionally, guest speakers are invited to present on topics under discussion in class, to present the practitioner viewpoint and their experience of the legal issue under discussion. This marrying of the worlds of academia and practice serves a number of purposes; it emphasises the social significance of the law in practice, triggers an awareness amongst students of their own capacities to effect 
change including providing access to justice after they graduate, and to recognise their current capacities as law students to contribute to social change through their clinic and other commitments. Ultimately this first principle of multiple means of representation aligns with the accepted view that there is no one optimal way of presenting information or transferring knowledge. An awareness of the need for students to receive information in disparate ways is crucial to the creation of a module that can inform all attending students and the incorporation of multiple means of representation serves to provide the students with a positive first engagement with the material being delivered, which in turn better allows Meyer and Rose's two remaining principles of UDL to be achieved.

The second principle is multiple means of expression including expression in action. A key aspect of education across most disciplines is the development of transferrable skills that can be utilised to navigate the learning, and the expression of that learning. The focus of this second principle is a recognition of the multiple means of expression in the development of legal knowledge and the importance of providing appropriate supports and structures to allow for those multiple forms of student expression. Limitations in capacity to express knowledge can arise for physical and cognitive reasons, can be personality driven or can be inhibited through fear and/or lack of knowledge and/or capacity. However, the essence of education is the capacity to develop learning and abilities from wherever a student's starting point is, and thus utilising UDL ought to result in an approach which facilitates all forms of 
expression whilst nurturing the development and enhancement of every student. Evidently, ensuring capacity and support for multiple means of expression requires a module that provides alternate options for students in developing and sharing their knowledge and views. The Family Law Clinic absolutely strives to provide such a range of opportunities for the students.

"The Family Law Clinic provided a different type of learning from the lecture based academic type learning usually associated with an academic course. The family law Clinic bridged the academic aspect of law with the practical application of law. The work I undertook at the Clinic involved me having to improve greatly on my research skills, IT skills, presentation skills and co-working skills. I also learned significantly more about law in practice on a day to day basis. I gained considerable knowledge on a number of areas of law as a result of both the work I undertook on various topics and as a result of the work undertaken by other students. I learned also about group dynamics and the importance of learning to respect other peoples' positions and points of view." 44

A second, complimentary aspect of this principle is the importance of providing support scaffolding for the students. The capacity for students to develop when

\footnotetext{
${ }^{44}$ Student I.
} 
mentored and guided is well documented ${ }^{45}$ and the unique opportunities and supports provided in the course of the Family Law Clinic have been expressly recognised by participating students as key to their learning journey and overall abilities within the LLM (Children's Rights and Family Law).

“My involvement with the Clinic has improved my understanding of certain areas of family law as a result of the research I have done for the blog and the website content. It has also improved how I communicate more complex ideas to a varied audience.... I have wholeheartedly enjoyed the experience and have relished the challenge of communicating and discussing the law with the widest possible audience." $^{46}$

Students are invited to submit all written work and research assignments in draft form for feedback no later than one week in advance of the submission date, in order to highlight any shortcomings, allowing them to avail of an opportunity to learn in action and submit an enhanced piece of work for grading. Methodology sessions are also run in conjunction with the module learning, to allow for a broader understanding of the importance of critical thinking when conducting research at

45 “Campbell T.A and Campbell D.E "Faculty/Student Mentor Program: Effects on Academic Performance and Retention" [1997] 38 Research in Higher Education 727-742. https://link.springer.com/content/pdf/10.1023\%2FA\%3A1024911904627.pdf 46 Student $\mathrm{F}$ in interview. 
masters level, and in parallel the students are provided with library and related skills workshops to assist them in conducting relevant and meaningful research and critical capacities.

\begin{abstract}
"Participating in the Family Law Clinic has enhanced any performance in all my other modules. It has helped me to clarify for myself the law and the issues in that learning environment, enhancing my learning in the more didactic seminars."
\end{abstract}

The third principle is multiple means of engagement. Rose et al note that the differences in student capacities and interests will result in markedly different modes of student engagement and motivation. Tasks which require student spontaneity provides the perfect forum for expression for some students but for others they present a frightening and intimidating demand. Individual research and presentation tasks allow some students to excel in their own right and present an opportunity for showcasing such strengths. However equally other students thrive in a supportive peer-shared endeavour, buoyed by the different skills presented by each student, resulting in the collective tackling of the assignment with each student adopting the role most suited to their individual skills.

"I feel that my public speaking abilities and confidence grew significantly over the course of this module. The small number of 
students in the Family Law Clinic made it easier for me to speak my opinions and give contribution and input when it was required. This is a skill that I feel will continue to benefit me when I am finished my Masters." ${ }^{47}$

Online blogs provide an alternative non-class based, almost private assignment for students to engage with their work, away from the more exposed classroom environment, challenging the students to write in an accessible, non-academic style, without reliance upon legislation, case law or academic analysis. Interestingly students report annually that this is their hardest writing task throughout their LLM year in that it flips their 'trained' academic writing style and demands simplicity of message and style....a mammoth challenge for some but a welcome and refreshing approach for others!

"Writing a blog was a first for me. I liked the freedom of the genre compared to a typical legal assignment. However, one had to deal with the law accurately. It is still a work in progress as I must incorporate suggestions from Dr. Crowley into my blog and re-submit it. I never took part in debates, either at second or third level. Long ago, before I ever went to university, I was a trade union activist, so I'm used to rough house debates or loud, verbal disagreements. Perhaps if

\footnotetext{
47 Student D.
} 
blogging had been on the scene back then I would have been more successful. As I said I like the freedom of blog writing, but I also like the conventions that stop a blog from being a rant. I do believe that is a new skill I am learning." ${ }^{48}$

The quality of the work presented is tremendous, with one student, who had no background in law prior to commencing the LLM having her blog published in a national newspaper in $2017 . .^{49}$

Evidently the common denominator in the UDL approach is the acknowledgment of the importance of a diverse and varied approach to all aspects of teaching and learning in order the recognise and respect the multiplicity of student capacities and the importance of providing a range of opportunities to engage with and express the learning. Whilst students are expected to participate and contribute to each aspect of the workload, the format allows them to excel in those areas that suit their capacities whilst working to improve less proficient areas, typically with the support of both peers and the Clinic director. Accessibility is a multi-layered and complex issue and real effective access occurs on multiple levels and is essential to a complete and comprehensive student learning experience.

\footnotetext{
${ }^{48}$ Student E - Learning Journal.

${ }^{49} \mathrm{https} / / / \mathrm{www}$.irishexaminer.com/viewpoints/analysis/grace-case-must-prompt-reform-after-fostercare-scandal-shocked-the-nation-393063.html
} 
"It is not just enough to make classrooms and text books accessible, effective learning environments need to address three main issues. They need to provide information and informational supports that are accessible to all students, provide ways of acting on information that are accessible to all students and provide ways of engaging and motivating learning that are accessible to all students. The UDL principles reflect those 3 aspects in the design of learning environments." 50

The Clinic is deliberately modelled on the principles of UDL and seeks to facilitate and stimulate all participants to maximise engagement and learning.

"In reflecting on the learning and self-development that the module has offered, I realise that at a very practical level, this module was very useful as it facilitated both individual and group research in practice. Coming to the course without a primary law degree has been at times a bit daunting. This module enabled me to undertake legal research in a manageable realistic manner. As the tasks assigned were not overwhelming, I was able to take each task individually on board, and incrementally build on my research skills and knowledge. Having a

\footnotetext{
${ }^{50}$ Butler B, McCarthy M What Does Multiple Intelligence's theory and practice have to offer universal design for learning?" Background Paper to plenary session on Multiple Intelligences and Universal Design for Learning 12 March 2019; referencing the work of Rose et al.
} 
social work knowledge also helped as the tasks of the module were real, live and relevant to many parts of my previous work experience. I enjoyed the reading and the group work exposed me to the thinking of a much younger generation, who were generous in sharing their ideas and knowledge." 51

\section{Learning and Teaching as Community Property}

In the first instance, those responsible for the delivery of modules must value their teaching and see it as a community property much like research that is ubiquitously shared and celebrated on the conference circuit. Schulman criticises the pedagogical solitude of the classroom, the distinction that is drawn between teaching and research, noting how we share our research amongst a community of scholars yet tend to regard teaching as a more private endeavour. Rather he regards learning and teaching as best approached as a community endeavour with students, where possible, recognising the role that they can play in determining the module direction, the scope of the course materials and the achievement of shared objectives. The Family Law Clinic has been designed to provide scope for experimentation of content and allows students to have a say in the direction of the seminar content. In seeking ultimately to enhance access to information and thus justice, the participating students have a valuable role to play in identifying both new projects and the enhancement of existing ones, to fulfil this overarching mandate. This allows

${ }^{51}$ Student K - Learning Journal. 
the responsibility for both the content and delivery of the learning and teaching process to be shared between the lecturer and the students. It also allows students to feed into the teacher's process of problem discovery, as espoused by Bass. Bass is critical of the notion of teaching as a private endeavour that focuses on the mere identification of solutions to teaching challenges. ${ }^{52}$ Rather he regards the true teaching riches to exist in "discovering problems worth pursuing". ${ }^{53}$ Bass supports the views of Laurillard ${ }^{54}$ that teaching should not be regarded as a "normative science"; it ought not to be presumed that it can be done 'right'....rather he states it can be done effectively or ineffectively but always better. Such capacity for constant interrogation and improvement underlies the need for the scholarship of teaching movement. Similarly, Shulman advocates for the creation of artefacts to capture the "richness and complexity" of teaching in order to make it visible in the same way that we celebrate what he refers to as "more traditional forms of scholarship." 55

The Family law information website is a vital tool in providing the students with an insight into the challenges faced by ordinary citizens to access and understand the law in order to understand and vindicate their own rights. From a pedagogical perspective it introduced to the design of the Family Law Clinic, a novel, innovative assessment tool to engage with the students and allow them to explore and express

\footnotetext{
${ }^{52}$ Supra n.23.

${ }^{53}$ Ibid.

${ }^{54}$ Laurillard D Rethinking University Teaching: A Framework for the Effective Use of Educational Technology (London) Routledge 1993

${ }^{55}$ Supra n. 27 at 7.
} 
issues of family law in an entirely different format, and to do so with a significant level of autonomy. By providing the students with the capacity to express their learning in a forum such as the family law information website, they are empowered to bridge the chasm which can restrict public engagement with the law by maintaining and enhancing the tools to assist the broader community. Peruginelli acknowledges that the "[L]aw is the operating system of our society" noting how it regulates all human activity and the associated enforcement of all governing provisions. In regarding access to law as "a fundamental issue of social policy" Peruginelli concludes that "full availability of legal information represents the strategy to even out access to law for everybody." 56

The student experience has proven to expose the students to the fundamental importance of access to information as a gateway to access to justice, and an associated realisation that such access can be challenging for many.

"The way the law is written makes it inaccessible for many. We need another way; we need to do more. Like our work on the blogs for the website, makes it accessible." 57

\footnotetext{
${ }^{56}$ Peruginelli G Law Belongs to the People: Access to law and Justice Legal Information Management 16 (2016)107-110.

${ }^{57}$ Student $\mathrm{D}$ in interview.
} 
In maintaining the online family law information hub ${ }^{58}$ and publishing their individual blogs on topical issues of family law, the students develop an awareness of the importance of law as a tool for civil society but also citizen empowerment, and the threat to individual and societal wellbeing where such access is frustrated or prevented. This civic and community contribution speaks to the express aim of UCC to function as a place of learning in the community and for the community. The UCC Civic and Community Engagement Plan "Together With and For Community" identifies the university's overarching goal in the period 2017-2022, to become "more Connected, Visible and Engaged with and for Community". Ultimately the vision enunciated by UCC is to be a leading civically engaged University, through capitalising on our teaching and learning strengths, and translating our dynamic academic and research leadership into far-reaching community engagement for the good of all. ${ }^{59}$

\section{Student Reflections through Reflective Journals and Student Interviews}

The reflective learning journal represents the student account and associated reflections on their Family Law Clinic learning journey. Morrison lauds the growing

\footnotetext{
${ }^{58}$ The Family law information website www.familylawinformation.ie is essentially an information hub for all aspects of family law. Whilst providing a short narrative on the basic rights and/or issues arising under each heading and sub heading, it also acts as a central hub for existing resources within the State, which can be of assistance to those in need. Thus, rather than reinventing the already existing information resources, the Website acts as a signpost of sorts, directing the users to those existing services. Additionally, given the very high rates of lay litigants before the Irish family law courts, assistance and information is also provided in respect of court applications, including resources for court forms, details of procedures and possibilities of legal representation. Access to information is a very real obstacle for many and where access to information is impeded, access to justice is effectively thwarted.

${ }^{59}$ https://www.ucc.ie/en/media/centralmedia/UCC Civic Engage 2017a.pdf
} 
popularity of reflective practice at third level, allowing for student reflection on, and lecturer monitoring of, "personal, academic, professional and evaluative development", contributing to "notions of student "empowerment". ${ }^{60}$ As a research method to investigate the learning arising from student engagement with Family Law Clinic activities, it provides a forum for the student voice to be heard through the individual reflections upon the learning journey and the interrogation of these student learning journals is an important aspect of the research undertaken here. The learning journal represents a shift from the social, shared learning space of the classroom space to the personal, more private reflections of each student. In this context students are asked to consider their own role, not only in the classroom dynamic, but also more broadly, allowing them to begin querying their responsibilities as law graduates. This student reflection, both in action and on action, allows for the development of a self-awareness surrounding the student learning trajectory, inculcating a greater awareness of their personal and academic development. ${ }^{61}$

Describing their Clinic contributions provides each student with the opportunity to recount the nature and extent of their work, awakening in them if necessary, a

\footnotetext{
${ }^{60}$ Morrison K (1996) “Developing reflective practice in higher degree students through a learning journal"(1996) 21:3 Studies in Higher Education, 317-332 DOI: 10.1080/03075079612331381241

${ }^{61}$ In maintaining their reflective journals students are required to present their deliberations in a semistructured format; providing a description of their contributions to the Clinic activities and to reflect on their own associated learning as well as presenting their views on the Clinic experience more broadly.
} 
realisation of the intense but valuable workload involved in the 12-week experience of the Family Law Clinic. In setting out their contributions, the enunciation of their learning journey begins. Whilst the iteration of the various assignments, individual and group efforts is a useful exercise in itself, perhaps more significantly the student reflections on the semester of work commences properly at this point of the journal. Their website responsibilities are taken very seriously, highlighting the importance they attach to information hub contributions, in such a challenging and personal area of the law. It is imperative that the information is accurate but also presented in a manner that takes account of how the public will experience the information on the website. The unique approach adopted by each individual student, facilitated by the autonomy that the Clinic affords them, starts to become more apparent as the students outline their contributions. Student B outlines how in assessing her allocated sections of the website she chose to consult with friends and family members to gain an insight into how the existing content and layout is perceived and understood by the very audience to whom it is directed.

"This involved consulting with family members and friends as to the accessibility of the website since the provision of easily accessible information to the public is a key aim of the website. This exercise was hugely beneficial in gaining an insight into the thoughts of those who lacked any prior knowledge of family law and thus enabled me to adapt the website accordingly where required." 
This innovative and proactive approach illustrates the community property underpinning of the module activities and demonstrates how the module framework encourages independent student research activity. This scope for student novelty is also celebrated by Student E when outlining his contributions to the website.

"I gave a small questionnaire to 4 people, two of whom were graduates, two not. Two were men and two were women. The response was mostly favourable, and the non-graduates said the language was easy to understand."

Student D provides a useful overview of the range of tasks and associated skills required in outlining her contributions to the Clinic. In particular she references her research work for the National Women's Council of Ireland and the "valuable learning experience" of working with a classmate on the proposed changes to the Family Law civil legal aid system. In particular she notes that they

“.... came from two different undergraduate backgrounds so I found it very interesting to combine knowledge and experience. Furthermore, I found that the knowledge I gained on this area became applicable in other modules and really highlighted the need for the reform of the Irish Family Court system." 
In outlining her research work for Anne Marie Sheridan, solicitor, in respect of the District Court appeal relating to the use of the father's surname on the birth certificate of the client's child, Student D recounts the experience in positive terms.

"What I found most enjoyable about this task was a number of weeks after the activity was completed that Solicitor whom we worked for joined us in the Clinic. She spoke with us about her work and the outcome of cases that we had worked on. I really enjoyed this aspect of the Clinic and found that meeting her in person really made the research process real and for me personally was fantastic motivation at a stage in the year when the work load was high and we were feeling a little overwhelmed."

Similarly, referencing her research on the effects of mediation in the context of domestic abuse for the work of the National Women's Council of Ireland on the proposed new Family Law courts, student A stated that..."This was one of the most enjoyable assignments that I completed as part of the Clinic as I got to research an area that I had not studied before and gained valuable research skills which will be useful in future assignments and my thesis." The student experience documented in the reflective journals is very impressive, referencing a breadth of learning, including personal development, greater social awareness, and improved communication skills. In terms of social awareness, evidently the various assignments that sought to 
enhance access to information and/or the law taught the students that "[T]he law affects every person and so there must be more investment in ensuring that it is accessible to as many people as possible." 62

The overriding message from the student reflections are the multiple benefits arising from the scope of the learning offered by the combined elements of the delivery and assessment in the Family Law Clinic. The reliance upon group work for the completion of module tasks, introduced a novel approach to study and research for some students, more typically used to independent academic endeavour.

"An important skill the Clinic has taught me is the ability to work as part of a group. Compared to the other modules I have taken in my undergraduate and postgraduate degree, which were usually individually marked assignments, the Clinic encouraged engaging with our fellow classmates. The first assignment I worked on involving the barring order question spilt the class in half. This was a great opportunity to get to know some of the other postgraduates. It also gave us the opportunity to utilise our skills and strengths. In this particular group project, I was in charge of editing the question and referencing it. I also found it useful how other people in my group approached the question and we encouraged each other when we

\footnotetext{
62 Student A.
} 
found new material to contribute to the assignment. The second assignment involved myself and one other student. This was a particularly stimulating assignment as we both approached the assignment from completely different angles. It was also very interesting to be paired with someone who had a completely different educational background to mine." 63

In parallel, the varied means of expression incorporated through both engagement and assessment challenged the students to develop or improve a range of communication skills.

"My ability to communicate law in a straightforward and easily understandable manner has benefited from the completion of this module. The process of reviewing the accessibility of the website has enabled me to become more aware of the difficulties some people may have with understanding legal concepts at a time of crisis in which most family law cases will arise. This skill is, of course, essential to the administration of justice and to legal practice." 64

\footnotetext{
${ }^{63}$ Student A.

${ }^{64}$ Student B. Student $C$ reported similar benefits: "The Clinic also enabled me to identify what my unique strengths are. Having studied psychology for my undergraduate degree, it allowed me to develop my skills in communication and critical thinking. Throughout the course of the clinic I applied these strengths to the work I was doing in the Clinic which in turn allowed further development."
} 
A further, very encouraging aspect of the student journals is the evidence that the module as a whole has allowed them to develop not only as law students but has supported their holistic development including aspects of personal confidence and capacity for public speaking.

"When reflecting on the Clinic I became aware that not only did it improve my understanding of the law but in fact it developed certain aspects of my character, such as my confidence. ${ }^{65}$

Similarly, Student D noted the positive impact of the clinic experience on her capacity to express her opinions in a more comfortable and confident way.

The student reflections demonstrate a learning experience that is varied, challenging and engaging. It serves as a platform for the personal and academic development of all students, irrespective of their strengths or abilities. It also exposes the students to new ways of learning which has a significant impact on other elements of the LLM programme. The inclusion of voices beyond the lecturer and student adds a further dimension to the student education. Overall, the unique academic and personal learning opportunities arising from participation in the Family Law Clinic are regarded by the students as positive and worthwhile experiences. Their exposure to

\footnotetext{
${ }^{65}$ Student C. She also added that "...Having confidence in oneself is very important if that person aims to pursue a career in law, so this aspect of the Clinic will benefit me throughout my professional career.
} 
the law in practice and their engagement with practitioners provides an insight not available elsewhere in their university studies.

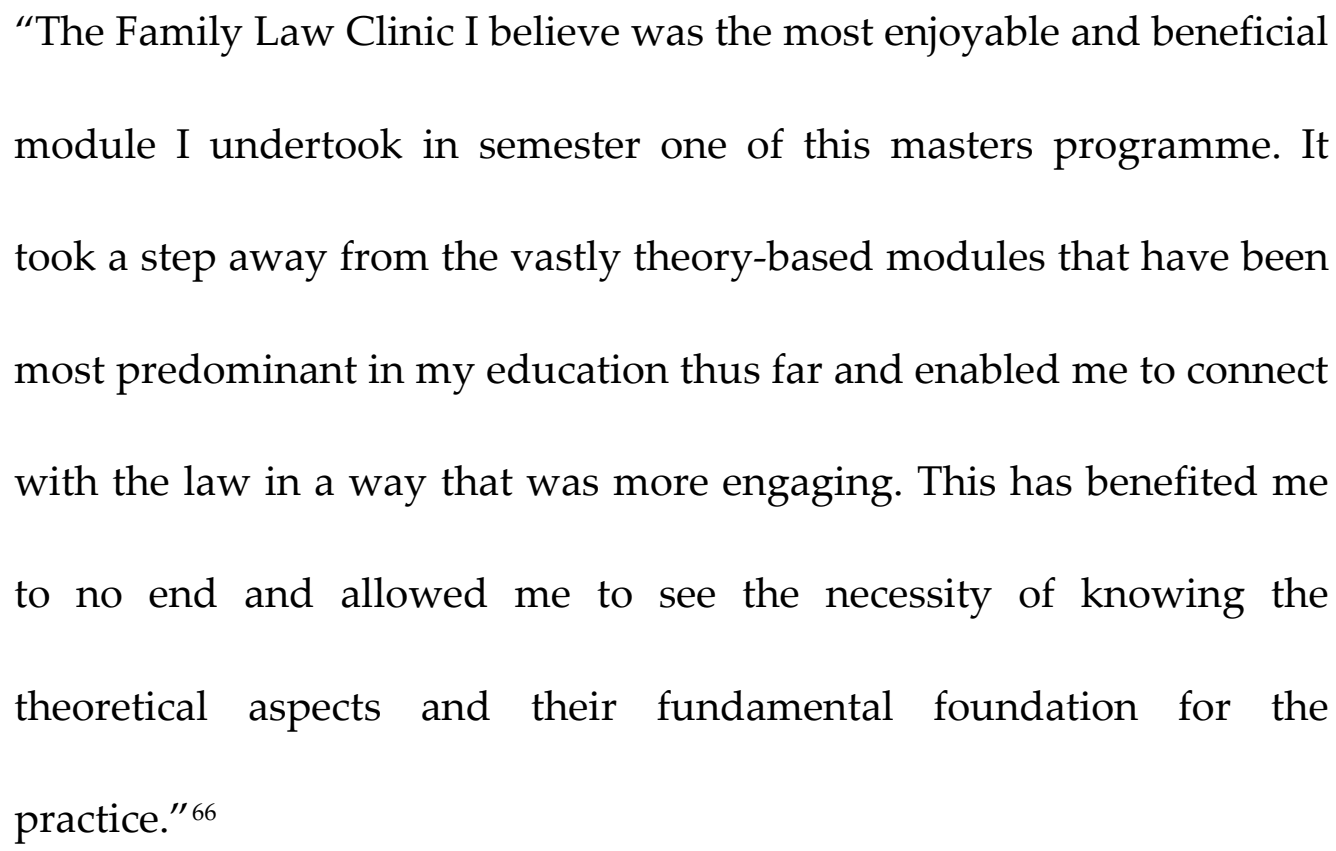

The breadth of the modes of delivery and the varied assessment obligations provide a meaningful opportunity for personal and academic development. Ultimately it is evident that the students' overall learning across the breadth of the modules studied, were particularly impacted by their Family Law Clinic experience.

"My experience of this module has been undoubtedly positive. The approach taken by this module is very progressive and unlike any other modules I have completed. The method of assessment and workload mirrors that of a practitioner. Often, we are faced with

66 Student C 
issues where the answer was not readily available and legal research was essential to finding the answer. This highlighted to me that no matter how knowledgeable or experienced you may be, new challenges will always arise since no two cases will ever be the same! The skills that I have developed through the Family Law Clinic will no doubt assist me in facing such challenges throughout my career." 67

Schon contends that one of the reasons for the growing focus on reflective practice in law is that "practice in these professions is often based on rapid action and the proof of expertise in the subjects emerges from the actions taken, not the quality of thought that might have gone into the actions". ${ }^{68}$ In delivering content to law students, it is too often readily accepted that transfer of knowledge is the limit of the lecturer's obligation. Conversely, in developing the Family Law Clinic and incorporating the reflective journal element, students are encouraged to not only gain a knowledge of the law, but also an understanding of the social context within which it is both understood and applied. The wisdom developed by these broader insights and the maturity and understanding that it is hoped will evolve from the students' reflection process, will result in a greater ability to reflect appropriately on the strengths and

\footnotetext{
${ }^{67}$ Student B.

${ }^{68}$ Moon J Reflection in Learning and Professional Development: Theory and Practice (Routledge Falmer 1999) at 55, citing Argyis C and Schon D Theory in Practice: Increasing professional effectiveness (JosseyBass publishers 1974).
} 
weaknesses of both the legal system and the students' own capacity to contribute to its effective and accessible operation.

“The Clinic has been a fantastic experience and has exceeded my expectations. In choosing this module and in general the Children's Rights and Family Law Masters, I wanted to get a hands-on experience of the material we would be covering. While each module we have is targeted towards learning and applying the law, the Clinic took a different approach by giving a sense of responsibility to the students as the work we were conducting was being presented to people outside of the UCC Law School. Furthermore ... the Family Law website offers an all-in-one stop of information that is understandable for the public. ... Being a part of the Clinic also provided a sense of pride within myself due to the practical nature of the course, making me aware that I was playing an active part, albeit a small part, in the changes that are needed in the area of family law, which made the work all the more satisfying." 69

By engaging in reflective practice, students develop and foster critical thinking and decision-making skills, not only in respect of their Clinic and broader LLM learning, but ideally these skills are transferable and applicable throughout their careers. In 
developing a capacity for reflection and associated informed, progressive learning in action, students cultivate skills for continuous improvement and learning. Rolheiser et al assert that meaningful learning evolves from student reflection, resulting in

"...the capacity for students to improve their ability to think about their thinking; the ability to self-evaluate - the capacity for students to judge the quality of their work based on evidence and explicit criteria for the purpose of doing better work; the development of critical thinking, problem-solving, and decision-making; and the enhancement of teacher understanding of the learner." 70

\section{The External Practitioner - as Clients of the Clinic}

Testimonies from external legal practitioners who have relied upon the research services of the Clinic provide an external stakeholder critical commentary on the workings and impact of the student endeavours. External engagement is a key component of a successful law school, given the importance of maintaining positive connections with the professions and related service providers, for the benefit of student placements, for the development of positive and mutually beneficial working relationships and to ensure that the broader society also benefits from such collaborations. In analysing the work of the Clinic, this objective professional

\footnotetext{
${ }^{70}$ Rolheiser, C, Bower B and Stevahn L The Portfolio Organizer: Succeeding with Portfolios in your Classroom. Alexandria, VA: Association for Supervision and Curriculum Development (2000) at 31-32.
} 
feedback provides an important critical perspective of the effect and impact of the work being conducted and can lead to enhanced opportunities to develop future relationships and student prospects. In the 2018-19 academic year the research services of the Clinic were utilised by three distinct external legal practitioners and interest groups, namely the National Women's Council of Ireland, the Family Lawyers Association of Ireland and Anne Marie Sheridan solicitor.

The Clinic dealt directly with Ms Denise Roche, the legal officer in the National Women's Council of Ireland who reached out to the Clinic for research support in respect of two key issues on the Council's 2019 agenda. Denise was leading the Council's research in response to the Irish Government's stated intention to reform the Irish family law courts system. Denise identified three distinct approaches worth considering within the Irish context. Denise's written testimonial demonstrates the importance of the efforts of the Clinic in supporting the work of the National Women's Council of Ireland, a leading and influential Irish public interest group.

“The ability to work with a clinic such as this, is essential for me to be able to carry out my role. NWCI understands the lived experience of women but in order to accurately represent them, I must be able to underpin their testimony with statistics and factually drawn analysis. Facts take time to develop, and given the numerous demands on my role, I have limited capacity to dedicate the required time to develop 
detailed, accurate and comparative research papers. Moreover, the ability to produce up to date research requires access to the most recent academic research which means it's imperative to have access to legal research databases. The cost of these databases is not within the limited financial means of my organisation. Therefore, the Family Law Clinic enables me to acquire highly relevant research without having to dedicate the time or resources to develop it." 71

She also acknowledged the multiple benefits of this approach, not only in terms of teaching and learning, but also the benefits that accrue to students at this pivotal time of their career, often on the brink of making career path decisions; as well as the positive impact on the work of the NWCI and on society more broadly.

"I think this clinic is also of benefit to the students. They can see the practical application of their work and how essential it is to be able to produce accurate, detailed and rapid information. It also offers them an insight into the workings of small organisations, and the importance of well-developed research and writing skills. I hope as

\footnotetext{
${ }^{71}$ Additionally, Roche referenced the reputation of the Clinic Director in the field of family law research and teaching and noted the weight and credibility that this attaches to the work of the Clinic as a whole. "I felt confident in relying on the information provided because it was delivered under the supervision of Louise Crowley. A highly qualified academic who understands the feminist perspective that NWCI wishes to communicate through all our work. I can confirm that the research I received was produced within a short timeframe and cut straight to the core of the issues."
} 
they move through their careers that this helps foster in them the importance of engaging in pro bono work. Much of what I am able to achieve in my role is as a direct result of lawyers, academics and students offering their expertise for free. I hope to be able to work with the clinic into the future particularly as the reform of the family court system continues."

In October 2018 the Irish Family Lawyers Association approached the Clinic to seek research support in advance of their annual national conference which the UCC School of Law had agreed to host on campus in February 2019. The theme of the conference was the enforcement of family law orders and the Clinic was tasked with providing an international comparative perspective for the workshop discussions. Diverse and effective approaches to enforcement were identified in four distinct jurisdictions; Canada, Denmark, Sweden and New Zealand and the students worked in groups to conduct in-depth research and produce a dossier which, once approved by the Director of the Clinic, was made available to all attendees at the conference. The research dossier formed the basis of a broad and well-informed debate on the future direction for the enforcement of family law orders in Irish courts and the quality of the research was highly commended by those in attendance. ${ }^{72}$

\footnotetext{
72 "The students' preparation of the dossier of research was excellent and a very helpful tool in structuring the discussion." (Sarah Fennell BL - conference organiser)
} 
Finally, the students had a valuable multi-layered learning experience in collaboration with Anne Marie Sheridan solicitor, in relation to two District Court appeal cases which required research support and an ongoing inter parent dispute concerning the home schooling of their child. The first District Court appeal related to the legal capacity for an individual to make joint applications for remedies in the context of domestic violence allegations, to ensure that one remedy would ultimately be secured. The second case, related to the right of a mother, not married to the father of her child, to use the father's name on the birth certificate of the child, without the father's consent. Additionally, in the latter case, it was queried whether the court could over-rule any objections of the father and compel the Registrar of Births Deaths and Marriages to register the birth in the father's name. As distinct from the research conducted for the National Women's Council of Ireland and the Family Lawyers Association, and indeed most research in the course of their LLM generally, this engagement with Anne Marie Sheridan exposed the students in a most unique way to the operation of the law in practice. Their understanding of the usefulness and impact of their work was vividly illustrated by Anne Marie when she subsequently attended a clinic seminar to provide the students with this insight. Anne Marie reported her capacity to utilise the research to both negotiate effectively and present enhanced legal arguments to achieve successful outcomes for her clients. The students in turn, whilst benefitting from completing the research assignment, also gained a valuable understanding of the process involved, including factfocussed research, the reality of contemporaneous twin approaches of negotiation 
and proceeding to trial, and an insight into the broader challenges of family law litigation. Equally satisfying was the mutuality of this benefit as espoused by Anne Marie in her reflections of the experience. As a busy family law practitioner, she captures the importance of the Clinic research and the manner in which it enhances the level of advocacy in the lower courts, where because of the workload pressures, the time to engage in vital research in respect of family law issues is typically impossible without support.

\footnotetext{
"The key to the District Court is to have each case prepared fully in advance of the court. I have been able to seek the assistance of the FLC to research the law and the case precedents to assist me in running the cases. It also gives me the option of a complete fresh look at a set of facts and sometimes a completely different outlook on the case."
}

With reference to presenting an issue for determination not previously addressed by Anne Marie, she notes the significance of the Clinic contribution to enhance her capacity to present the best case for her client.

“This year, I was retained by the Legal Aid Board to act on behalf of a client seeking to home school her son. Her ex-husband did not consent. The FLC and members of the UCC staff were of huge assistance in my preparation. I was fortunate enough to have the opportunity of 
meeting with the students and giving them the feedback of the cases which we had worked on together. Having the personal connection with the students and Dr. Crowley opens the way to maintaining a mutually beneficial relationship." 73

\section{External Academic Examiner}

Finally, the views of the academic external examiner of the module and the broader LLM programme ensures that the context of the Family Law Clinic is always to the forefront, that whilst it operates as a service for the public and the professions, it remains embedded in the academic LLM programme on Children's Rights and Family Law and thus must always serve the interests of the students as an academic module which enhances their learning and their postgraduate experience more broadly. All aspects of the student learning experience are considered by the External examiner who must be satisfied as to the depth of the student learning and their ongoing engagement with academic learning, albeit in the context of that learning impacting on law in practice.

\footnotetext{
${ }^{73}$ The commendations of Anne Marie Sheridan provide an endorsement not only of the work of the Clinic but also the way the Clinic is conducted. This speaks volumes about the students' commitment and dedication to pursuing the fundamental goals of the Clinic and serves as a welcome validation of the merit in adopting this approach to developing the skills of our LLM students. "I have recommended the FLC to my colleagues who were equally delighted to have such an opportunity open to them. I expect the students are delighted to hear their law in action and make it a living subject for them."
} 
Professor Maebh Harding Warwick University has commented as follows:

"I have always been impressed by this initiative and it is clearly going from strength to strength. It is great to see such engagement and impact. You have clearly got a very engaged bunch of students. I thought that the work I read was of a very high standard."74

\section{Conclusion}

"The Clinic opened up my mind, and it never switched off" 75

The Family Law Clinic at University College Cork represents a deliberate effort to engage with postgraduate students in a manner which empowers them to better understand the challenges of pursing legal remedies and to explore their capacities to support access to the intricate Irish legal system. By creating a module design which requires students to contribute to public knowledge and engagement, the Clinic seeks to achieve the complementary goals of scholarship and community of learning through multiple means of representation, expressions and engagement.The experience to date in delivering the module is that it has developed into a key aspect of the student learning, providing LLM students with a novel and innovative space to explore the law in practice and to better understand the significance of access to the law and the dangers that exist for those who are

\footnotetext{
${ }^{74}$ Feedback received on student assignments submitted in the 2018/19 academic year.

${ }^{75}$ Student B.
} 
prevented from accessing information, and thus justice. Through qualitative research methods the process of designing and delivering the Clinic, which goes beyond the transfer of legal knowledge and seeks to deliver that learning in a practical context has been explored and has sought to provide considered insight into the student learning experience. It has been demonstrated that the student learning in the course of completing the Family Law Clinic has impacted positively on all other aspects of the LLM experience and activates a process of learning in action and longer-term reflective practices in the participating students.

In creating multiple avenues for the students to amass and present their learning to a multiplicity of audiences, they are provided with an opportunity to recognise their capacity to use their law school education, and in particular the Clinic setting to enhance the community experience of justice. Citing Cooper J and Trubek L, Webb stresses that legal education needs to be seen as a process of "educating for justice ... citizens' access to justice must in part be predicated on the ability of lawyers and judges themselves to show an understanding of and commitment to "justice". ${ }^{76}$ Interestingly Webb regards the development of that commitment to justice as a function of the universities that must be incorporated in the legal education provided. In better understanding the importance of real access to information and thus justice, the students in the Clinic develop this better understanding of what real

\footnotetext{
${ }^{76}$ Webb J “Developing Ethical Lawyers: Can Legal Education Enhance Access to Justice?" (1999) The Law Teacher 3:3, 284-297. https://www.tandfonline.com/doi/pdf/10.1080/03069400.1999.9993035?needAccess=true
} 
justice means. They begin to understand the law in context, the role of the law in the community, as both as a social tool and as a means to vindicate and protect individuals. The over-arching message is that law in itself does not operate to secure rights, securing rights necessitates real access and an understanding of the context and application of the law, and the Clinic provides the insight into this reality. Remembering always that "if all we teach students is law, we cannot expect them to practice justice..."77, the Family Law Clinic has been designed to broaden student learning and empower them to develop a sense of community awareness and responsibility that transcends their student lives and remains with them long after graduation to direct the use of their enhanced awareness, knowledge and skills. ${ }^{78}$

\footnotetext{
${ }_{77} \mathrm{Ibid}$ at 286, referencing the works of Elytis and the need to make explicit, the link between ethics, education and access to justice; Elytis Odysseus The Axion Esti (translated by Keeley E and Savidis G) (1980) London, Anvil Press.

${ }^{78}$ Webb echoes this hope, suggesting that we ought to always remember to teach students that lawyering involves responsibility to and for others.
} 